\title{
New Method for Nanosecond Laser Machining
}

\author{
Cinthya Toro ${ }^{*}$, Carlos Lasorsa ${ }^{*},{ }^{* *}$, Citlali Sánchez Aké ${ }^{* * *}$, M. Villagran-Muñiz ${ }^{* * *}$ and Carlos Rinaldi ${ }^{*, * * * *}$ \\ * Comisión Nacional de Energía Atómica, San Martín, Prov. de Buenos Aires, Argentina. \\ E-mail: ctoro@cnea.gov.ar \\ ** Universidad Tecnológica Nacional (UTN), Regional Haedo, Argentina. \\ **** Laboratorio de Fotofísica, CCADET, UNAM, México D. F., México. \\ ${ }^{* * * * *}$ Consejo Nacional de Investigaciones Cientificas y Técnicas (CONICET), Argentina.
}

\begin{abstract}
The technique of micro-machining assisted by laser is the most recent and flexible process for the design of complex devices. To be able to micro-machine hard materials with precision it is necessary to study the parameters that control and limit the capabilities of this laser process. Several articles have shown that if it applies a lot of energy in a localized area there are hot-affected zones (HAZ), even when a femtosecond laser is used. Hence, the challenge in the laserbased micromachining is to improve the quality of machining, i.e. depleting the HAZ in the prototypes. In this work, changing the optical properties of the substrate, good quality silicon micro-machining has been obtained with a nanosecond Q-switched laser.

DOI:10.2961/jlmn.2012.03.0007
\end{abstract}

Keywords: Nanosecond laser, thin films, silicon nitride, silicon dioxide and silicon (100).

\section{Introduction}

Micro-machining assisted by laser is the most recent and flexible process to develop prototypes in several substrates like polymers, metals, semiconductors, ceramics, etc. [1-3]. It is known that if a lot of energy is applied in a localized area there are hot-affected zones (HAZ). So, the main challenge of the material processing with laser radiation is to avoid or reduce damage and debris. Though in the last years the attention has been put in the practical use of these effects [2, 4].

Exhaustive studies with femtosecond (fs) have been done in order to study the morphologic variations of single-crystal silicon (c-Si) and c-Si coated with $\mathrm{SiO}_{2}$. It was determined that this variation depends of both the laser radiation and the material of the piecework. In this way, it is possible to control damage morphology to improve the capabilities of the machining system [5].

Results of laser-processing of metals shows that the thermal effect of laser radiation cannot be entirely avoided even by using a fs laser. There are formations of melt and HAZ. This is due to the interaction of ultrashort laser radiation and the atmospheric gas in the laser-focal region. These effects can limit the machining precision severely [4].

On the other hand, $\mathrm{Si}_{3} \mathrm{~N}_{4}$ films are widely used in solar cells fabrication. Because of that, the optical properties of this film modifies the absorption of the surface workpiece. A. Grohe et al. made experiments focusing in obtaining a process as damage-free. Note that the parameters need to be chosen in a way that the selectivity of the ablation process is as high as possible. They found that this selectivity depends on the absorption coefficient of the different materials $[6,8]$.

In this work we compare the effects of short pulse duration during the machining when the substrate is covered with thin films. The objective is to improve the quality of machining using a nanosecond (ns) pulse laser together with a thin films of $\mathrm{SiO}_{2}$ and $\mathrm{Si}_{3} \mathrm{~N}_{4}$.

\section{Experimental}

In this regard, it was used a micro-machined system which consists of: an $8 \mathrm{~ns}$ Q-switched Nd:YAG (532 nm, $250 \mathrm{~mJ} / \mathrm{cm}^{2}, 10 \mathrm{~Hz}$ ) from Spectra Physics, a 3 axis stage with its drivers from ThorLabs (NanoMAX300), a collimator (pinhole of $2 \mathrm{~mm}$ diameter), a lens ( $\mathrm{f}=75 \mathrm{~mm}$ ), a software ad-hoc which synchronizes the laser pulse with the movement of the sample (see Figure 1).

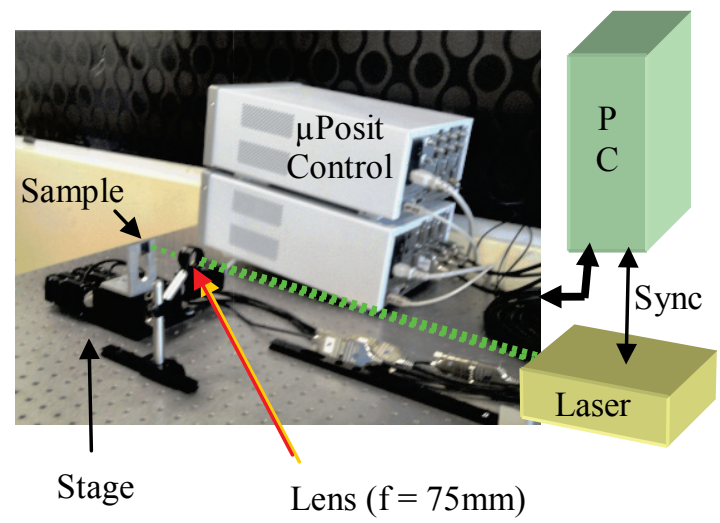

Fig. 1 Photography of part of the micromachining system with a scheme for the PC connections.

The sample was fixed to the stage and moved in front of the laser (see Figure 1). Almost all the time the laser was pulsed every $300 \mathrm{~ms}$.

In this machining system, the process was divided into two parts: first, the parameters of micro-machining were established, and in second term, it was manufactured the device. It needs to know the conditions of material removal (light energy, number of pulses, focal length and the mechanics of the movements required) to fabricate the prototype.

The samples were p-type single-crystal silicon $<100>$ wafers, c-Si, with $0.640 \mathrm{~mm}$ thickness and $20 \mathrm{~mm} \times 10 \mathrm{~mm}$ 
size. To obtain thin films of $\mathrm{SiO}_{2}$ and $\mathrm{Si}_{3} \mathrm{~N}_{4}$ it was used a PE-CVD method.

\subsection{Deposition Conditions}

The gas flow enters at the opposite end to the location of the substrate, producing plasma which provides the gas in ionic form and the free electrons needed to break the bonds of the organic compound, allowing the subsequent recombination of the elements thus obtained the formation of the coating. The flow of gases in individual processes is regulated by an automatic flow controller (MFC), the characteristics of the team allowed to vary the relative flows of oxygen without varying pressures. The deposition process was developed at one stage, the substrate was thermalized to $750{ }^{\circ} \mathrm{C}$ and $800 \mathrm{~V}$ BIAS potential. The coatings were made on c-Si substrates.

Process conditions:

Gas flow $\left(\mathrm{N}_{2}\right.$ or $\left.\mathrm{O}_{2}\right) 30 \mathrm{sccm}$.

150 mTorr pressure.

Deposition rate of $3 \mu \mathrm{m} /$ hour.

Average hardness $1 \mathrm{GPa}$.

The reactions that give rise to coatings are:

$$
\left(\mathrm{CH}_{3}\right)_{3} \mathrm{SiNHSi}\left(\mathrm{CH}_{3}\right)_{3}+\mathrm{N}_{2} \rightarrow \mathrm{Si}_{3} \mathrm{~N}_{4}+(\mathrm{TBD})
$$

Reactions with $\mathrm{O}_{2}$ are as follows:

$$
\mathrm{SiOH}+\mathrm{SiOH}+\mathrm{O}+2 \mathrm{H}=\mathrm{Si}-\mathrm{O}-\mathrm{Si}+2 \mathrm{H}_{2} \mathrm{O}
$$

The coating sought aims to stop the attack of $\mathrm{Si}<100>$ (stop etching) performed with $\mathrm{KOH}$ in aqueous solution, 35 gr. $\mathrm{KOH}$ in 65 gr. $\mathrm{H}_{2} \mathrm{O}$ at $80^{\circ} \mathrm{C}$ and should ideally be the thickness of $1 \mu \mathrm{m}$, and low residual stress.

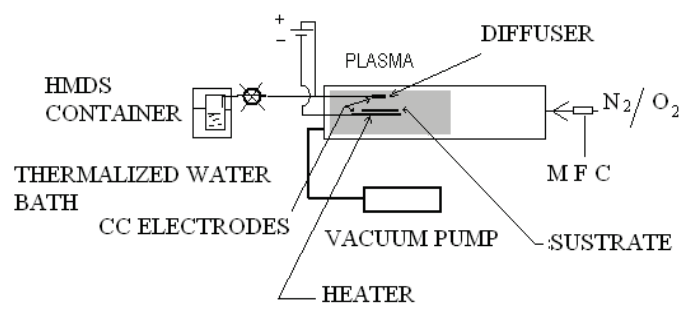

Fig. 2 Schematic illustration of the PE-CVD reactor.

With the experimental equipment described in Figure 2, (glow discharge), there were $\mathrm{Si}_{3} \mathrm{~N}_{4}$ and $\mathrm{SiO}_{2}$ coatings at temperatures $700{ }^{\circ} \mathrm{C}$, using a mixture of Hexamethyldisilazane (HMDS) $\left(\mathrm{CH}_{3}\right)_{3} \mathrm{SiNHSi}\left(\mathrm{CH}_{3}\right)_{3}$ and nitrogen or oxygen in individual processes [9][10].

\section{2-1- 1 Films characterizations}

The coating chemical elements and their bonding condition were characterized using X-ray photoelectron spectroscopy (XPS) (Vacuum Generator Mod. ESCA 3 MARK II). The X-ray in XPS was generated at $10 \mathrm{kV}$ and $20 \mathrm{~mA}$, using $\mathrm{Mg} \mathrm{K} \alpha$ radiation $(\mathrm{hv}=1253.6 \mathrm{eV})$. The air pressure in the vacuum chamber was $7 \times 10^{-9}$ Torr. The depth profile analyses of the near surface regions were carried out by sputtering with Ar+ ions using a current intensity of $6 \mu \mathrm{A}$ and an acceleration voltage of $5 \mathrm{kV}$ (ion current, $8 \mu \mathrm{A}$ ) at an argon pressure of $8 \times 10^{-5}$ mTorr. The XPS was corrected for charge shifting by taking $\mathrm{C} 1 \mathrm{~s}$ at $285.0 \mathrm{eV}$. All the experiments were conducted at room temperature. Figure 3 is shown the X-ray spectra of crystalline films of $\mathrm{Si}_{3} \mathrm{~N}_{4}$.

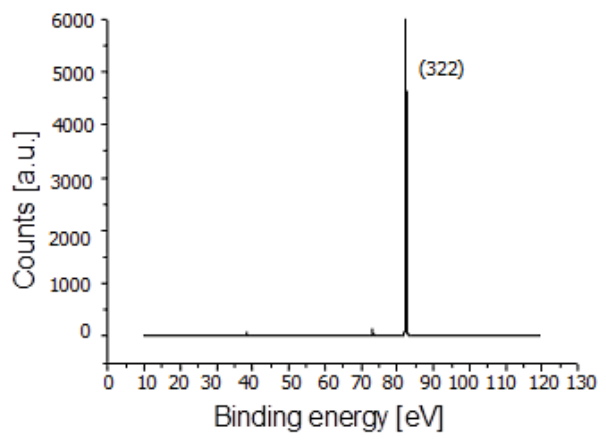

Fig. 3 X-ray spectra showed crystalline films simple hexagonal structure with preferential direction (322).

FTIR spectra (for characterization of film functional groups) of covers obtained were recorded in a Nicolet MAGNA 560 instrument equipped with a liquid $\mathrm{N}_{2}$ cooled MCT-A detector. One of this is showed in Figure 4.

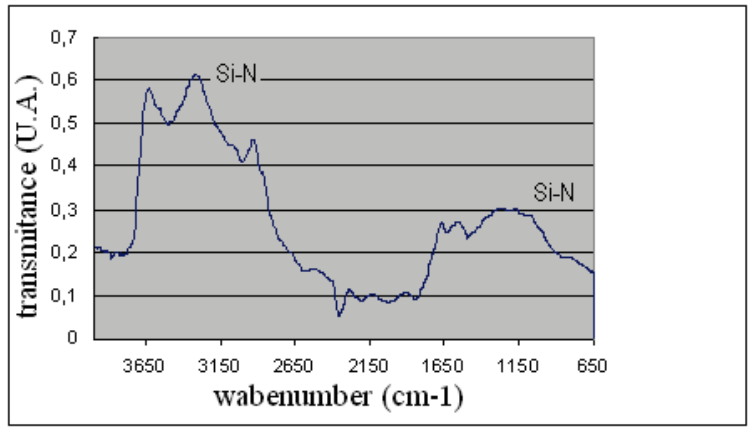

Fig. 4 FTIR spectra in the range $4000-650 \mathrm{~cm}^{-1}$.

The coating microstructure was characterized by SEM (scanning electronic microscopy) using a FEI model QUANTA 200 (see Figure 5). Thickness was measured using a mechanical profiler (Mitutoyo Mod. Surftest SV400) and microhardness (Akashi Mod. MVK-H2). In addition, plasma emission optical spectroscopy (OES) (SPEXMod. 1870 spectrometer) was used in the spectral range $300-500 \mathrm{~nm}$ in order to identify the species in the plasma at a distance of $3 \mathrm{~cm}$ in front of the substrate surface, as well as to evaluate changes in the emission spectra as the oxygen flow rate was increased.

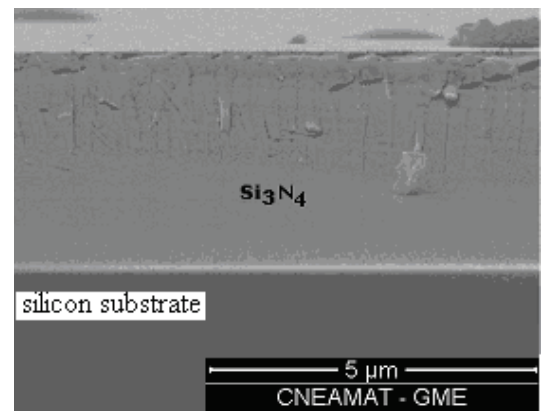

Fig. 5 SEM cross section view of the coating. 
The area of lower wave number is comparable to the observed spectra by $\mathrm{S}$. Yan and colleagues [11] $\mathrm{Si}_{3} \mathrm{~N}_{4}$ coatings on particles of $\mathrm{ZnS}$ activated with $\mathrm{Cu}$ which would indicate the formation of nitrides on the surface.

The films were grown over the c-Si and the following thicknesses were used:

$\mathrm{SiO}_{2}$ : $100 \mathrm{~nm}, 430 \mathrm{~nm}, 510 \mathrm{~nm}$ and $1220 \mathrm{~nm}$.

$\mathrm{Si}_{3} \mathrm{~N}_{4}$ : $180 \mathrm{~nm}, 420 \mathrm{~nm}, 570 \mathrm{~nm}$ and $960 \mathrm{~nm}$.

The samples were named as follow:

$\mathrm{c}-\mathrm{Si}+\mathrm{SiO}(\alpha \mathrm{nm})$ : $\mathrm{c}-\mathrm{Si}$ coated with silicon dioxide with a thickness of $\alpha \mathrm{nm}$.

c-Si+SiN $(\beta \mathrm{nm})$ : c-Si coated with silicon nitride with a thickness of $\beta \mathrm{nm}$.

\subsection{Machining process}

A matrix of $13 \times 15$ spots was made, with different fluencies in each sample. In Figure 6 it could see 3 samples with the grid machined.

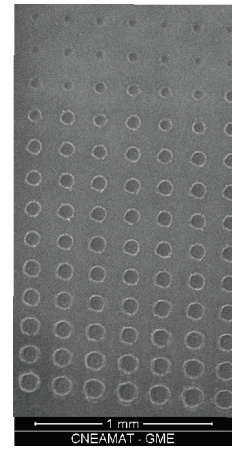

a)

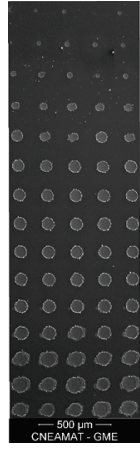

(b)

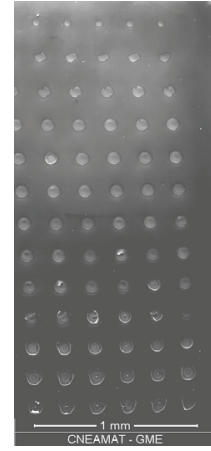

(c)
Fig. 6 Micrographs after irradiation of the samples. (a) c-Si (b) c-Si+SiO(100 nm), and (c) c-Si+SiN(570 nm).

Finally, to probe if the laser penetrates until silicon, it was used potassium hydroxide $\left(40 \% \mathrm{v} / \mathrm{m} @ 60^{\circ} \mathrm{C}\right)$ to do a selective etching. In Figure 7 it could be seen the sample of Figure 6 (c) after the etching.

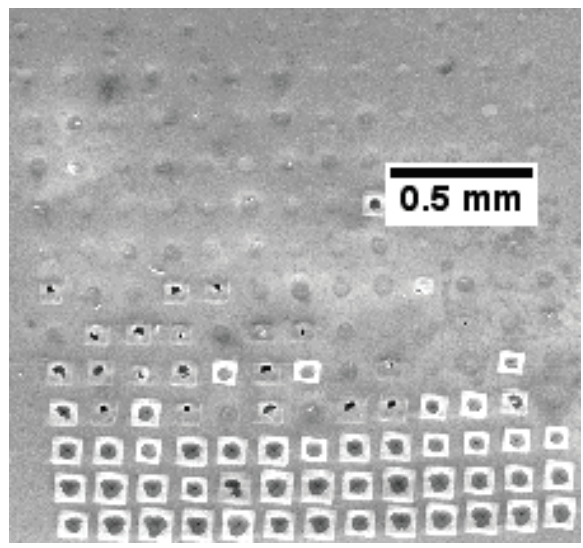

Fig. 7 Sample after selective etching (See the text).

\section{Results}

\subsection{Characterizations with a SEM (FEI Quanta 200)}

The irradiated samples were observed with a SEM in order to characterize the quality of the single laser shot.

Rows with 13 single shots were done for statistical propose. Every row had the same laser energy density.

In Fig. 6 it can be seen, as examples, that the diameters of the holes are increasing as a function of the laser fluence. In the same Figure the energy is increasing from top to bottom.

In the case of $\mathrm{c}-\mathrm{Si}+\mathrm{SiN}(570 \mathrm{~nm})$ (Figure 6(c)), it was observed that the laser did not reach the silicon at low fluencies. Because of this, the selective etching had made pyramidal holes at the last rows of the grid (See Figure 7). These types of holes are typical in the anisotropic wetetching in $\mathrm{c}-\mathrm{Si}$.

On the other hand, it was analyzed the quality of a single hole for each sample. Differents single shots are shown in Figure 8. The Figure 8(a), 8(b), 8(c) correspond to irradiation with ns laser, where the parameters are: 532 $\mathrm{nm}$ wavelength and $170 \mathrm{~mJ} / \mathrm{cm}^{2}$ of delivered fluence. The samples are: c-Si at Figure 8(a), c-Si+SiO(110 nm) at Figure $8(\mathrm{~b})$, and the Figure $8(\mathrm{c})$ has a $\mathrm{c}-\mathrm{Si}+\mathrm{SiN}(570 \mathrm{~nm})$ sample after the same irradiation.

Finally, in order to observe the effects of the fs laser ablation on the film, a sample of $\mathrm{c}-\mathrm{Si}+\mathrm{SiN}(570 \mathrm{~nm})$ was machined following the same procedure like the ns laser. The result is shown in Figure 8 (d). The laser used was a Ti:Zaphiro (127 fs pulse duration, $800 \mathrm{~nm}$ of wavelength and $300 \mu \mathrm{J} / \mathrm{cm}^{2}$ of delivered fluence).

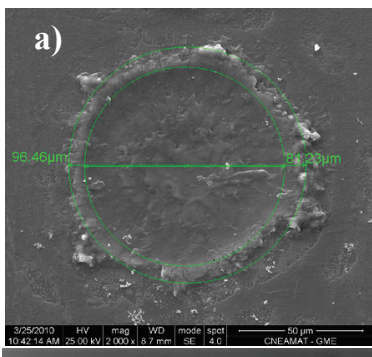

c)

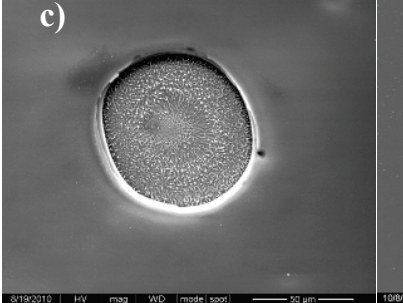

Fig. 8 Micrographs of single shots. See the text

\subsection{Characterization with an Optical Profiler}

To characterize the quality of the cavity it was used a Veeco Profiler (NT1100). In Figures 9 and 10 it could see the profile of holes in c-Si and c-Si+SiN(570 nm) with the ns laser. 


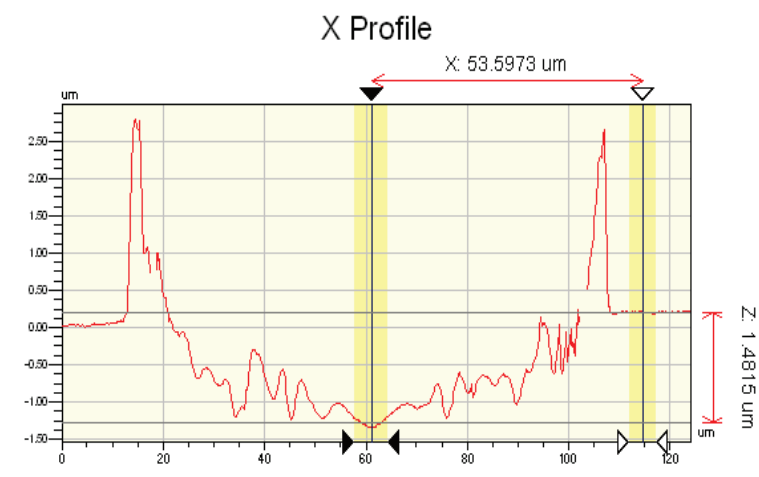

Fig. 9 Profile of one hole over the c-Si sample with ns laser at $170 \mathrm{~mJ} / \mathrm{cm}^{2}$.

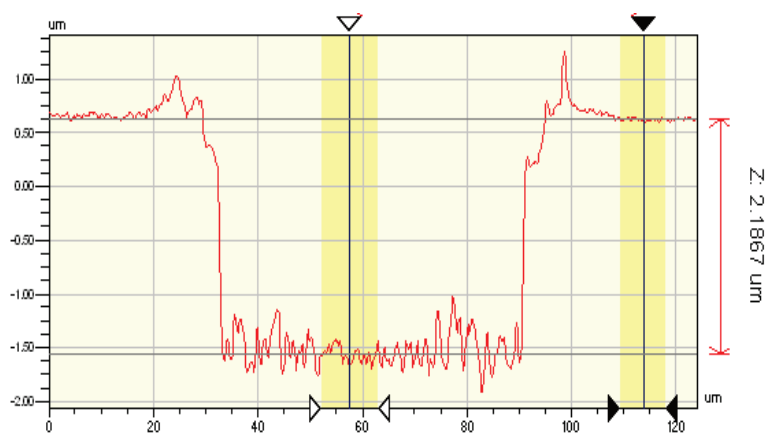

Fig. 10 Profile of one hole over the c-Si+SiN(570 nm) sample with ns laser at $170 \mathrm{~mJ} / \mathrm{cm}^{2}$.

When the c-Si+SiN(570 nm) was machined with ns laser at $170 \mathrm{~mJ} / \mathrm{cm}^{2}$, it was observed the same profiles in the $90 \%$ of the cases.

It was found, in c-Si irradiated with ns laser, that when it was increased the energy density, the deepness holes were $1400 \mathrm{~nm} \pm 200 \mathrm{~nm}$ (see Figure 11). On the other hand, in the case of the c-Si+SiN $(570 \mathrm{~nm})$, it was observed 550 $\mathrm{nm} \pm 20 \mathrm{~nm}$ for low fluence, and $2150 \mathrm{~nm} \pm 50 \mathrm{~nm}$ for fluences up to $150 \mathrm{~mJ} / \mathrm{cm}^{2}$ (see Figure 11).

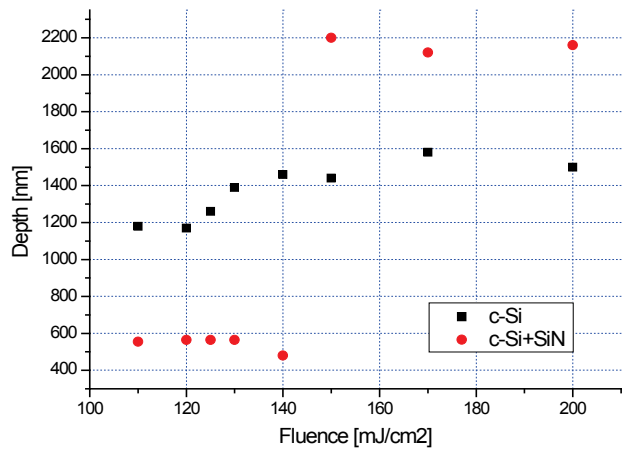

Fig. 11 The holes depths observed in c-Si and c-Si+SiN(570 nm).

About the diameters observed, see in Figure 12, for c-Si it was possible fitted with a logistic function which is in accordance with Bredicce et al. [12]. But for the c$\mathrm{Si}+\mathrm{SiN}(570 \mathrm{~nm})$, it had holes just when the laser reach the silicon. The diameters are between 80 and 75 microns with high repeatability.

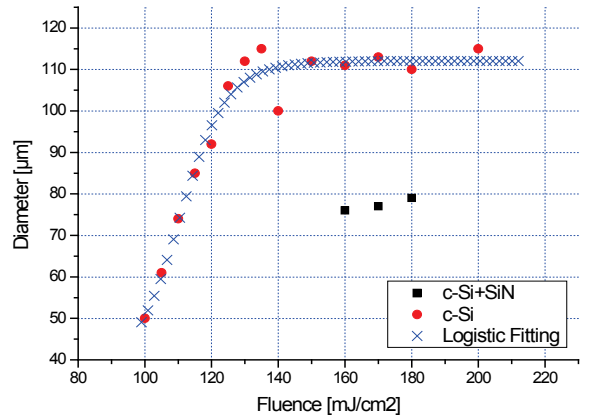

Fig. 12 The holes diameters observed in c-Si and c$\mathrm{Si}+\mathrm{SiN}$.

\section{Conclusions}

A good quality silicon micromachining has been obtained with a nanosecond Q-switch laser and covering the samples with thin films of $\mathrm{Si}_{3} \mathrm{~N}_{4}$.

At least for one pulse, machining system assisted by nanosecond laser using thin films:

a. enhanced the quality (HAZ decreased till $75 \%$ ) as can be seen in the Figure 8(a) compare with Figure 8(c),

b. present high verticality (Figure 10),

c. and have more than $90 \%$ of repeatability.

These results show a better quality using thin films in a micromachining assited by ns laser.

Nevertheless the mechanism of laser ablation when the substrate is covered with thin film is not completely understood, even when it was used a femtosecond laser.

The next step is to improve the quality of machining lines, but it would be necessary to change the shape of the spot.

\section{Acknowledgments}

We acknowledge the Materials and the GAIANN from CNEA for providing the electron microscopy facilities. Financial support of this work was provided by the Agencia Nacional de Promoción Científica y Tecnológica, Ministerio de Ciencia, Tecnología e Innovación Productiva (Argentina) and Consejo Nacional de Ciencia y Tecnología (México). Grammar and spelling check by Jesica Lasorsa.

\section{References}

[1] K. Sukioka, M. Meunier, A. Piqué: "Laser Precision Microfabrication" ed. by Springer - Series in Material Science, (Germany, 2010) Chapter 2, 10 and 13.

[2] A. Holmes, J. Pedder, K. Boehlen: Proc. of SPIE Vol. 6261, 62611E-1.

[3] M. J. Jackson, G. M. Robinson, Journal of Achievements in Materials and Manufacturing Engineering, Vol. 20, ISSUES 1-2, (2007) 452-454.

[4] D. Breitling, A. Ruf, F. Dausinger: Proc. of SPIE Vol. 5339, p. 49-63.

[5] B. R. Tull, J. E. Carey, E. Mazur, J. P. McDonald, and S. M. Yalisove: MRS Bulletin Vol. 31, (2006), p. 626633.

[6] M. Barrera, J. Plá, C. Bochi, A. Migliori: Solar Energy Materials \& Solar Cells 92, (2008), p.1115-1122. 
[7] S. M. Yang, J. Plá: Solid-State Electronics 53, (2009), p. 925-930.

[8] M. Abbott, P. Cousins, F. Chen and J. Cotter: Photovoltaic Specialists Conference, (2005), (Conference Record of the Thirty-first IEEE).

[9] C. A. Lasorsa, P. M. Perillo, P. J. Morando: Surface and Coatings Technology 204, (2010).

[10] C. Lasorsa, P. J. Morando, A. Rodrigo: Surface and Coatings Technology 194, (2005).

[11] S. Yan, H. Maeda, J. I. Hayashi, K. Kusakabe, S. Morooka y Y. Okubo, J. Mat. Sc. 28, 1829, (1993).

[12]F. Bredice, H. Sobral and M. Villagrán-Muni: Journal of Applied Physics, Vol. 98, (2005), 083305.

(Received: July 22, 2011, Accepted: August 03, 2012) 